\title{
A Review on Application of Computers in Education Inside and Outside of Iran
}

\author{
Hamid Reza Mahboudi ${ }^{*}$, Farahman Farrokhi², Ali Akbar Ansarin ${ }^{2}$ \\ ${ }^{1}$ University College of Rub-bi Rashid, Tabriz, Iran \\ ${ }^{2}$ Department of Foreign Languages and Literature, University of Tabriz, Tabriz, Iran
}

Corresponding Author: Hamid Reza Mahboudi, E-mail: hr_mahboodi@yahoo.com

\section{ARTICLE INFO}

\section{Article history}

Received: May 11, 2017

Accepted: July 16, 2017

Published: August 31, 2017

Volume: 8 Issue: 4

Advance access: August 2017

Conflicts of interest: None

Funding: None

\section{Key words:}

Technology,

Education,

Digital Natives,

High-source Settings,

Misapplication

\begin{abstract}
This paper first presents an overview of the Digital Natives claim made by Prensky (2001) and its characteristics. Secondly, focusing on the Iranian context, the paper examines the reports of UNESCO Institute for Statistics (UIS, 2014), the present state of ICT integration in education in national research, and the present state of ICT integration in education in international research. Reports and comparisons attest to the fact that Iranian educators have failed to realize their high expectations despite heavy financial investment in computer technology in schools and colleges. This review also provides some words of caution about computer technology to help policy makers and educators aware of the negative side-effects of misapplication of technology, the imposition of computer technology to imitate high-source settings, and the misuse of technology and its serious and long-term consequences. Eventually, this paper concludes that if a generation misapplied or underused technology, they should not be added to the list of Prenskey's digital natives so long as they are deprived of the qualitative and quantitative standards of high-source settings. Additionally, the impacts of technology on a generation need to be examined carefully before they are called digital.
\end{abstract}

\section{INTRODUCTION}

In Digital Natives, Digital Immigrants, Prensky (2001) wrote: "Our students have changed radically. Today's students are no longer the people our educational system was designed to teach.” (p.1)

As educational researchers argue, a new generation of learners is flowing into our educational centers, one which has acquired information and communication technology (ICT) since childhood. What makes these young people different from previous generations of students and from their teachers is their use of ICTs. Moreover, the differences are so significant that the nature of education itself must fundamentally change to accommodate the skills and interests of these 'digital natives' (Prensky, 2001a). In spite of the fact that such calls for radical modification in education are being widely proposed, they have undergone little critical investigation and have been embraced without empirical research in the educational context of Iran. The blindfold adoption of what was once called "western technology" and now "eastern technology", just to keep up with the rest of the world, has had negative impacts on the micro-level (individual) and macro-level (social) education. On a micro-level, the negative side effects of misapplication of technology has resulted in students' insomnia, academic under-achievement, sedentary lifestyle, isolation from pen and paper and modification of study habits in favor of distraction and procrastination. On a macro-level, this misapplication has damaged education by growing a pseudo-digital generation whose academic performance has now come into question. Iranian students' under-achievement has become especially evident in the early half of the $21^{\text {st }}$ century with the increase in utilization of Chinese electronic devices. The ironic part is that the more the Iranian new generation becomes digital as a result of utilizing multiple electronic devices, the more they disconnect from libraries, teachers, and pen and paper books in thought for whiling away the minutes by talking on the cell phone, net surfing, googling, chatting and texting through cell phone messaging apps. This is evident by the fact that students, upon entering classroom, reach for their electronic devices instead of pens and papers once the lesson begins. The issue then calls for a critical scrutiny and a theoretically informed research.

\section{The Tale of "Digital Natives"}

Prensky coined and popularized the term "digital native" in his 2001 article entitled "Digital Natives, Digital Immigrants." Prensky related the contemporary decline in American education to educators' failure to understand the needs of 
modern students. His article postulated that "the arrival and rapid dissemination of digital technology in the last decade of the $20^{\text {th }}$ century" had changed the way students think and process information, making it difficult for them to excel academically using the outdated teaching methods of the day. In other words, children raised in a digital, media-saturated world, require a media-rich learning environment to hold their attention, and Prensky named these children "digital natives". Prensky did not strictly define the digital native in his 2001 article, but it was later, arbitrarily, applied to children born after 1980, because computer bulletin board systems and Usenet were already in use at the time. The idea became popular among educators and parents, whose children fell within Prensky's definition of a digital native, and has since been adopted as an effective marketing tool. It is important to note that Prensky's original paper was not a scientific one, and that no empirical data exists to support his claims. He has recently substituted "digital wisdom" for digital native metaphor.

Prensky (2001) contrasts Digital Natives with Digital Immigrants-the name Prensky gives to those who were introduced to digital technology as adults. Unlike Digital Natives who were exposed to digital technology from childhood, Digital Immigrants think "slowly, step-by-step, one thing at a time, individually, and, above all, seriously." (p.2)

Consequently, Prensky not only calls upon Digital Immigrants to learn to use digital media themselves, but also demands that education systems be adapted to the way of thinking of Digital Natives. Some new forms of learning such as Game-based Learning and MOOCS (Massive Open Online Courses) were produced under the influence of such calls.

Apart from Prensky, Howe and Strauss (1991, 2000), Oblinger and Oblinger (2005), Palfrey and Gasser (2008) and Tapscott $(1999,2009)$ have postulated that today's generation behave differently to previous generations of young people because they have been exposed to networked and digital technologies since childhood. It is argued that they think differently, they learn differently, they exhibit different social characteristics and have different expectations about life and learning. Some have even claimed that the brains of students today are "physically different" (Prensky, 2001b) from earlier generations of students because of the students' early exposure to technology. This new generation of students is characterized as receiving information quickly, relying on communication technologies, often multitasking and having a low tolerance for lectures, preferring active rather than passive learning (Tapscott, 1999; Oblinger, 2003; Oblinger and Oblinger, 2005).

"In education they [the Net generation] are forcing a change in the model of pedagogy, from a teacher-focused approach based on instruction to a student-focused model based on collaboration.” (Tapscott, 2009, p. 11)

Besides "Digital Native/Digital Immigrants" (Prensky, 2001a, 2001b, 2009, 2010, Palfrey and Gasser 2008), there are also some other terms that refer to the same new generations of young people who have been brought up in a digitally rich environment. The most popular terms are the
"Millennials" (Howe and Strauss, 1991, 2000, 2003), "Net Generation" (Tapscott, 1998, 2009, Oblinger \& Oblinger 2005), "Generation Y" (Jorgensen, 2003; Weiler, 2005; McCrindle, 2006), the "IM Generation" referring to the Instant Message Generation (Lenhart, Rainie, and Lewis, 2001), the "Gamer Generation" (Carstens and Beck, 2005) for the obvious reference to video games, "Homo Zappiens" (Veen, 2003 ) for their ability to control information flows, and 'visitors' and 'residents' (Tall Blog, 2008) used to refer to someone who spends a proportion of their life online and someone who uses the Web as a tool to address their specific needs. Recently, new terms have made their way into the literature These terms are "Digital Melting Pot" (Stoerger, 2009) showing the integration rather than the segregation of Digital Natives with the Digital Immigrants, "Born Digital" (Palfrey and Gasser, 2008), suggesting that the term generation is an overstatement and that "population" is a better substitute.

Prensky (2001a, p.2) reported the key characteristics of digital natives as follows:

1. Digital Natives are used to receiving information really fast.

2. They like to parallel process and multi-task.

3. They prefer their graphics before their text rather than the opposite.

4. They prefer random access (like hypertext).

5. They function best when networked.

6. They thrive on instant gratification and frequent rewards.

7. They prefer games to "serious" work.

Likewise, Prensky (2001) reported the characteristics of digital immigrants as follows:

1. They think slowly.

2. They think individually.

3. They think step-by-step.

4. They think seriously.

Following these statements, other authors, such as Tapscott (1999), Oblinger and Oblinger (2005), Dede (2005a, 2005b), Tapscott and Williams (2010) and Palfrey and Gasser (2008), promoted the argument and encouraged the idea that education has to change because there has been a generational shift due to technological change.

There were some other authors who identified the new model of education for this generation as learner-centered, active, and collaborative. Tapscott and Williams (2010) argued that the traditional model of education is a broadcast model and that:

"A broadcast is, by definition, the transmission of information from transmitter to receiver in a one-way, linear fashion." (p 20)

As Jones and Shao (2011) indicated, advocates are also in favor of institutional reform and even claim that "universities must change in a radical pro-market and neo-liberal fashion in order to meet the challenges posed by the new generation of students." The authors of some of these ideas have a more radical agenda, one that predicates deep institutional change on the speculative arguments about the character of this new generation (Margaryan et al. 2011). Tapscott and Williams (2010, as cited in Jones, C. and Shao, B., 2011) proposed 
the adoption of a free market approach in which private initiatives and the market replace existing models of the university. The role of government, in their view, is to building the digital infrastructure, such as broadband networks, which would allow private commercial providers to succeed.

In short, Prensky and his followers argue that education has become so complicated that we have ignored our students' real needs. It is time to reconsider what good and effective teaching means in a digital age and how to combine what is important from the past with the tools of the future. Prensky (2012) argues that "despite recent influxes of technology into schools, not enough attention is being paid to the full implications of all the important recent changes in our educational environment and context".

However, Prenskey's brilliant ideas are not applicable to a developing country, like Iran, in which the young generation is struggling with the dominant traditional educational system and consequently engaging in counterproductive application of electronic devices.

\section{ANALYSIS OF ICT INTEGRATION IN EDUCATION}

\section{The Present State of ICT Integration in Education Iran}

E-readiness (electronic readiness) is a measure of the degree to which a country is prepared to partake in electronic activities and, thus, benefit from ICT in education (Dada, 2006). Based on UNESCO Institute for Statistics (UIS, 2014) released a report which starts by examining the policy and curricular aspects of ICT in education as fundamental to building a culture of ICT use in education. This is followed by an analysis of basic infrastructure required to support ICT-assisted instruction, including electrical and telecommunication capacity, numbers of computers, computer laboratories, ICT support services and Internet. The report further discusses limited data on participation rates amongst enrolments in programs offering ICT-assisted instruction by gender. Lastly, the report examines teacher preparedness, including relevant training for teaching basic computer skills (or computing) and on how to use ICT effectively in the classroom. The report assesses ICT integration and e-readiness using administrative data from 28 out of 32 responding countries across Central, South and West, and East Asia.

The tables and figures in this report provide the following summary about the present state of ICT in education in Iran.

1. In South and West Asia, Iran opted to include ICT in education within its national Master ICT Plan. Laws for the integration of ICT in education also exist for a number of countries, including Armenia, Azerbaijan, Indonesia, the Islamic Republic of Iran, Kazakhstan, Malaysia and Myanmar (see Figure 1).

2. Iran has integrated objectives or courses on basic computer skills or computing at primary, lower secondary and upper secondary levels of education.

3. Formal solutions to integrate ICT in all subjects and at all levels do not exist. Iran has set solutions for the integration of ICT in education in all subjects and at all levels, but not necessarily at each grade. Like Australia,
Azerbaijan, Georgia, Iran has a new course on business and technology which has been offered to Grade 6 students since 2013.

4. Like most countries in Asia Iran set approximately 1 to 5 hours per week for the use of ICT in education. However, the extent to which countries can meet these targets depends on several factors, including the availability of ICT in schools and teacher training to support its use.(see Table 1)

5. The integration of ICT into schools requires electricity (e.g., grid/mains connection, wind, water, solar or fuel-powered generator, etc.) that is regularly and readily available. Like most developed countries, electricity which is universally available in primary and secondary schools and in many middle-income countries is no obstacle to integration of ICT in education in Iran, demonstrating that basic electrical infrastructure is generally in place to integrate ICT in the classroom.(see Figure 2)

6. The learner-to-computer ratio (LCR) refers to the mean number of learners sharing a single computer available for pedagogical use in national, aggregate education systems. LCR sheds light on current infrastructure to support the integration of ICT-assisted instruction. Figure 3 shows the LCRs for primary, lower secondary and upper secondary education. At the primary level, data show that available computer resources are greatly overstretched in Iran (83:1).

5. Based on enrolment data from schools that offer CAI, the learner-to-computer ratio (LCR) in schools with computer-assisted instruction $(\mathrm{CAI})$ provides informa-

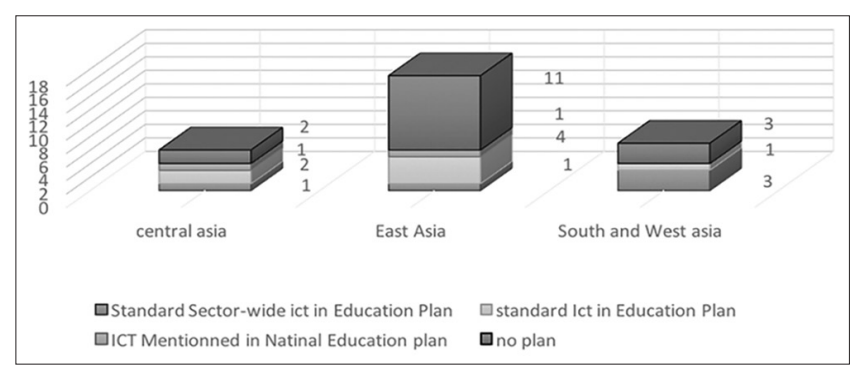

Figure 1. National plans to implement ICT in education, by type, 2012

Table 1. Institutional hours using ICT by level, 2012

\begin{tabular}{|l||c|c|c|}
\hline \hline & Primary & $\begin{array}{c}\text { Lower } \\
\text { secondary }\end{array}$ & $\begin{array}{c}\text { Upper } \\
\text { secondary }\end{array}$ \\
\hline \hline Cam bodia & - & - & $1 \sim 5$ \\
\hline Bhutan & - & $<1$ & $<1$ \\
\hline Philippines & - & $1 \sim 5$ & $\ldots$ \\
\hline Kyrgyzstan & - & $1 \sim 5$ & - \\
\hline Mongolia & $<1$ & $<1$ & $1 \sim 5$ \\
\hline Myanmar & $<1$ & $<1$ & $1 \sim 5$ \\
\hline Bangladesh & $1 \sim 5$ & $\ldots$ & $\ldots$ \\
\hline Iran & $1 \sim 5$ & $<1$ & $1 \sim 5$ \\
\hline Indonesia & $\ldots$ & $1 \sim 5$ & $1 \sim 5$ \\
\hline Azerbaijan & $1 \sim 5$ & $1 \sim 5$ & $1 \sim 5$ \\
\hline Georgia & $1 \sim 5$ & $1 \sim 5$ & $1 \sim 5$ \\
\hline Kazakhstan & $1 \sim 5$ & $1 \sim 5$ & $1 \sim 5$ \\
\hline Sri Lanka & $1 \sim 5$ & $1 \sim 5$ & $1 \sim 5$ \\
\hline Thailand & $1 \sim 5$ & $6 \sim 10$ & $11 \sim 20$ \\
\hline Malaysia & $11 \sim 20$ & $11 \sim 20$ & $11 \sim 20$ \\
\hline Armenia & $\ldots$ & $>21$ & $>21$ \\
\hline
\end{tabular}

Source: KERIS, 2013 


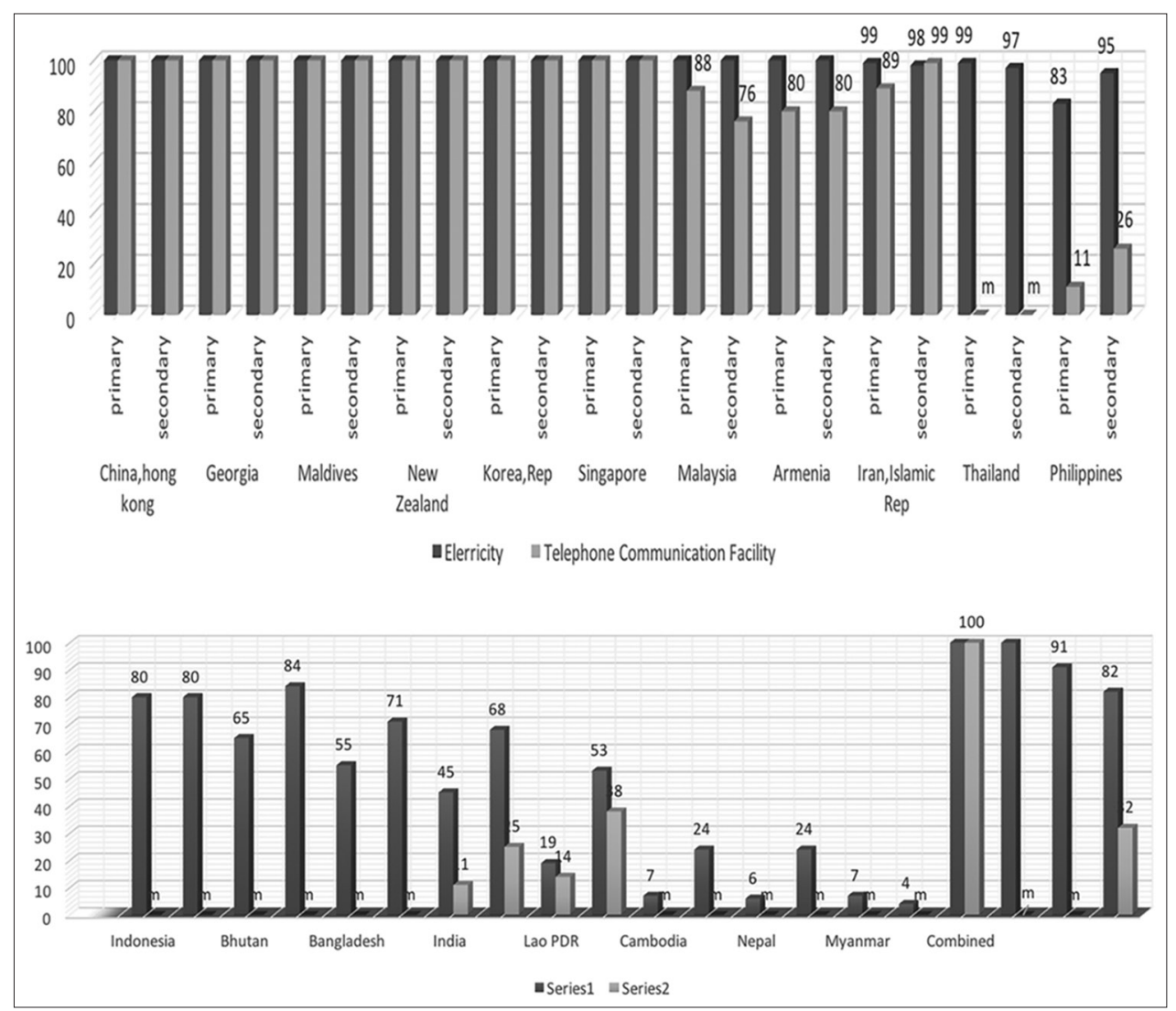

Figure 2. Proportion of educational institutions with basic electrical and telecommunications infrastructure by level of education, 2012

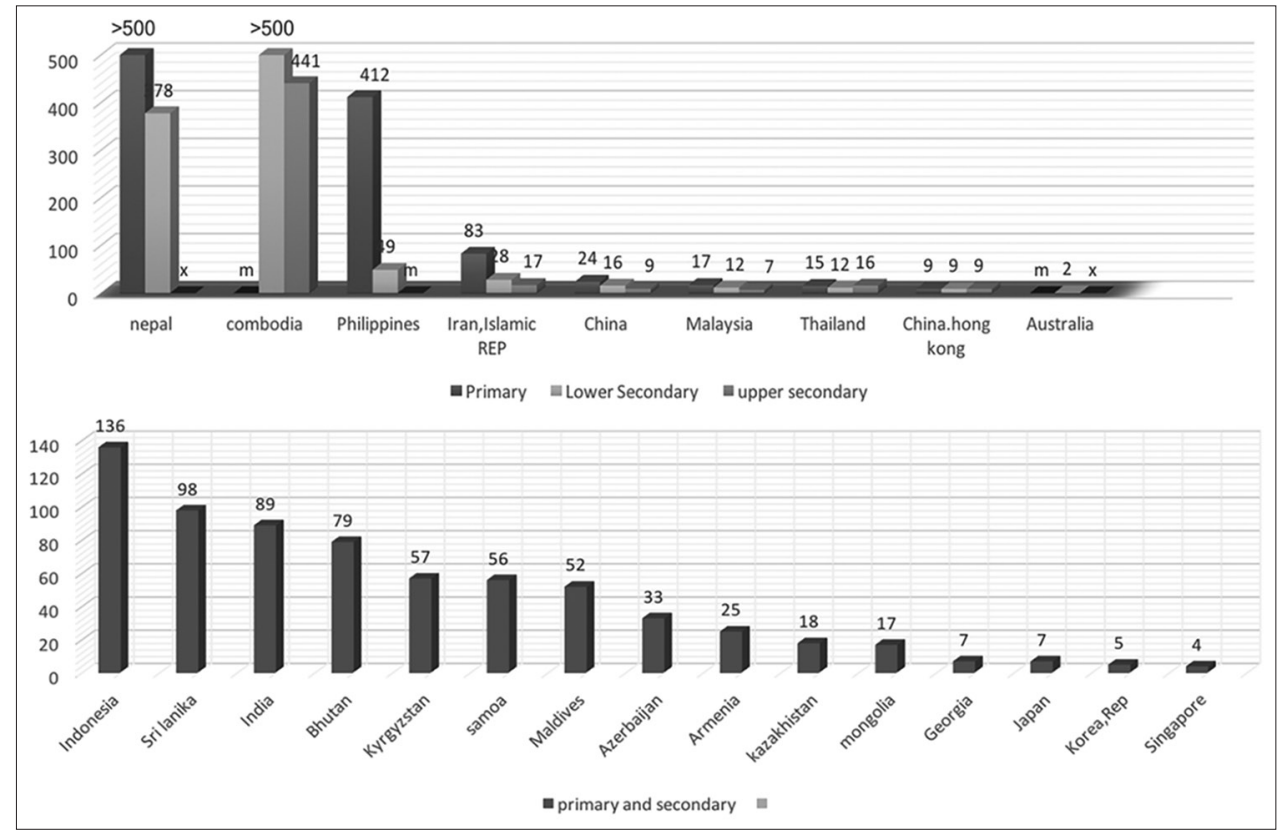

Figure 3. Learner-to-computer ratio (LCR) by level of education, 2012

tion on the availability of computers in educational institutions which use computers for pedagogical purposes and thus sheds light on the quality of the CAI offered. In Iran, the national LCR for primary education of 83:1 indicates scarcity of resources and relatively low access for pupils, compared to Singapore where the LCR is $4: 1$.

6. Iran as a middle-income country with relatively high LCRs allocates a small percentage of computers to ped- agogy. In the Philippines and the Islamic Republic of Iran, where primary LCRs are 412:1 and 83:1, respectively, $65 \%$ and $55 \%$ of computers are allocated to pedagogy. As such, there may be some latitude for the reallocation of computers in both countries.(see Figure 4)

7. Iran is an example of a country using a mixed model of providing computers in laboratories and other locations, such as classrooms or libraries. Based on Figure 7, 46\% 


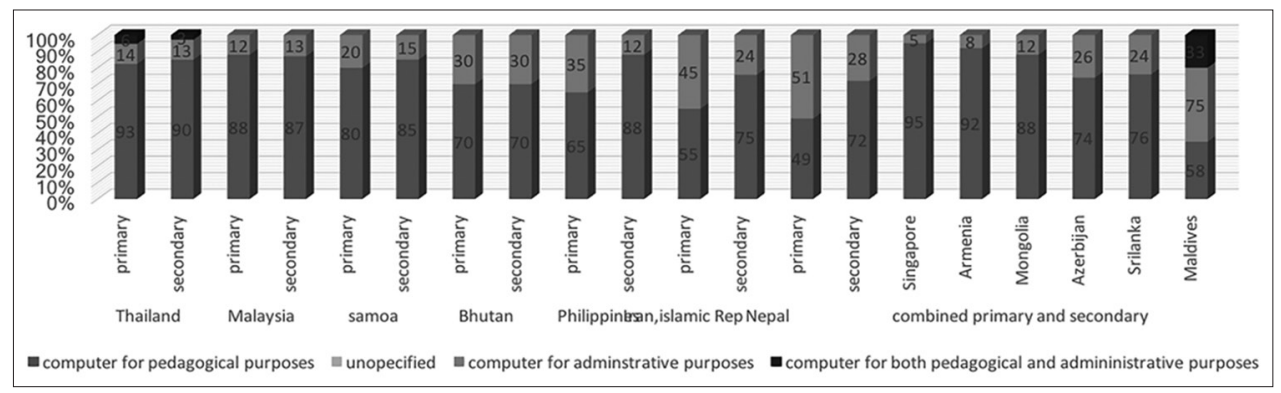

Figure 4. Computers in educational institutions allocated by purpose, by level of education, 2012

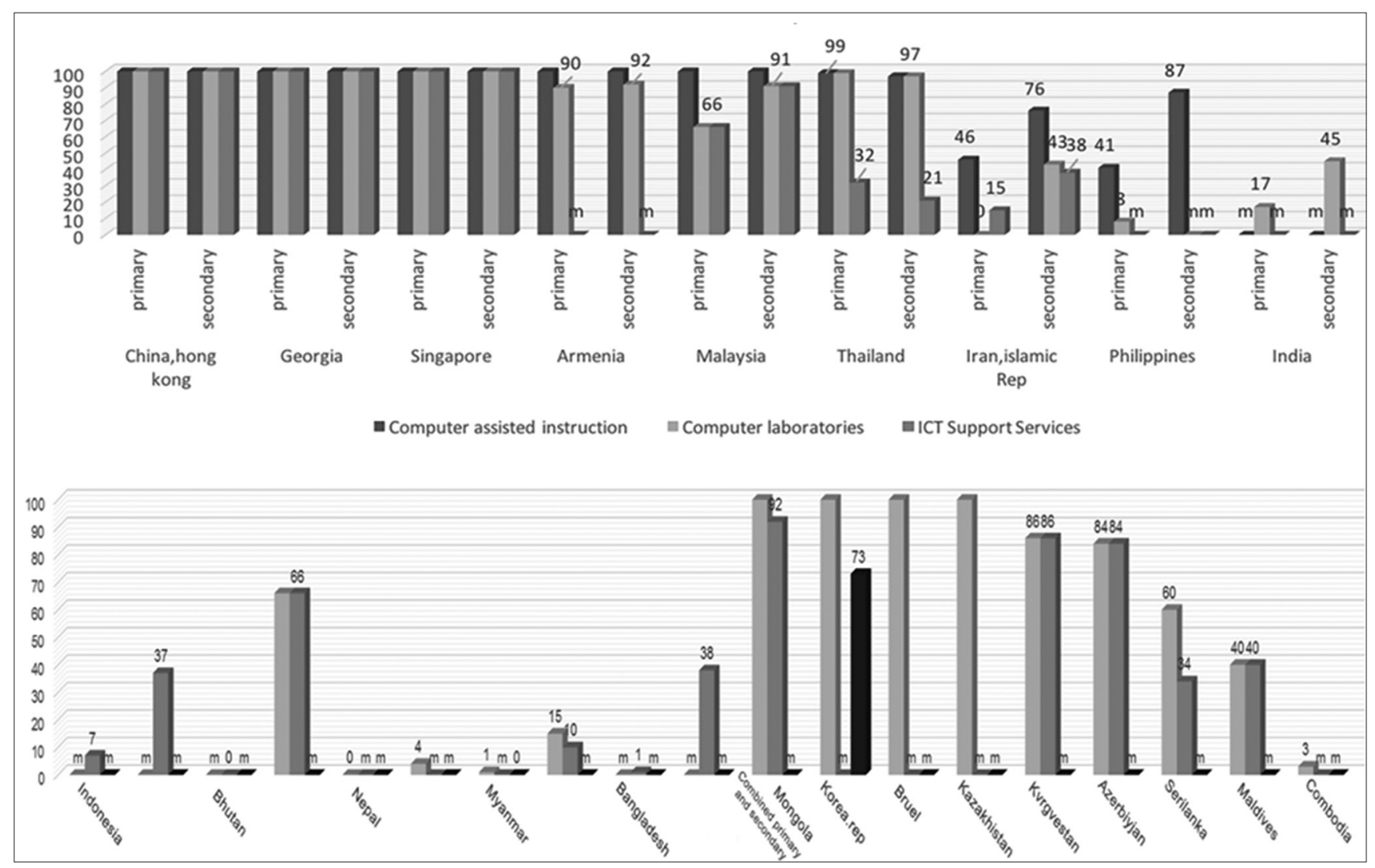

Figure 5. Computer-assisted instruction, computer laboratories, and ICT support services by level of education, 2012 Source: UNESCO Institute for Statistics database; Statistical Tables 3 and 4.

and $76 \%$ of primary and secondary schools, respectively, offer CAI, while no primary schools and $43 \%$ of secondary-level institutions have laboratories, suggesting computers are placed in different locations across schools.(see Figure 5)

8. Iran has also made progress in connecting its schools, with $74 \%$ and $89 \%$ of primary schools and secondary schools, respectively, being connected to the Internet, of which $54 \%$ and $74 \%$ are connected via fixed broadband. In Iran, only $11 \%$ and $36 \%$ of primary and secondary schools, respectively, use Internet to offer IAI, compared to the $74 \%$ and $89 \%$ that are connected. (see Figure 6)

9. Of the older forms of ICT-assisted instruction, radio-assisted instruction (RAI) and television-assisted instruction (TAI) have been used as educational tools since the 1920 s and 1950s. While some form of CAI is present in the majority of schools, IAI is only available in a small proportion of schools (6\%). Iran is limiting children's access to a full range of available online information and interaction. The existence of local area networks (LANs), however, may serve the role of mimicking some of the interactivity characterizing the Internet and worldwide web.(see Figure 7)

10. Teachers are frequently considered to be the most important influence on classroom learning and, as such, play an invaluable role in ensuring that pupils use ICT effectively inside the school. As Figure 8 indicates, 1\% of teachers are trained to use ICT. This lack of training leads to infective usage of ICT in teaching. This very important since poor or improper usage and management of ICT may, in fact, result in diminished educational outcomes compared to if no ICT had been employed.(see Figure 8) 


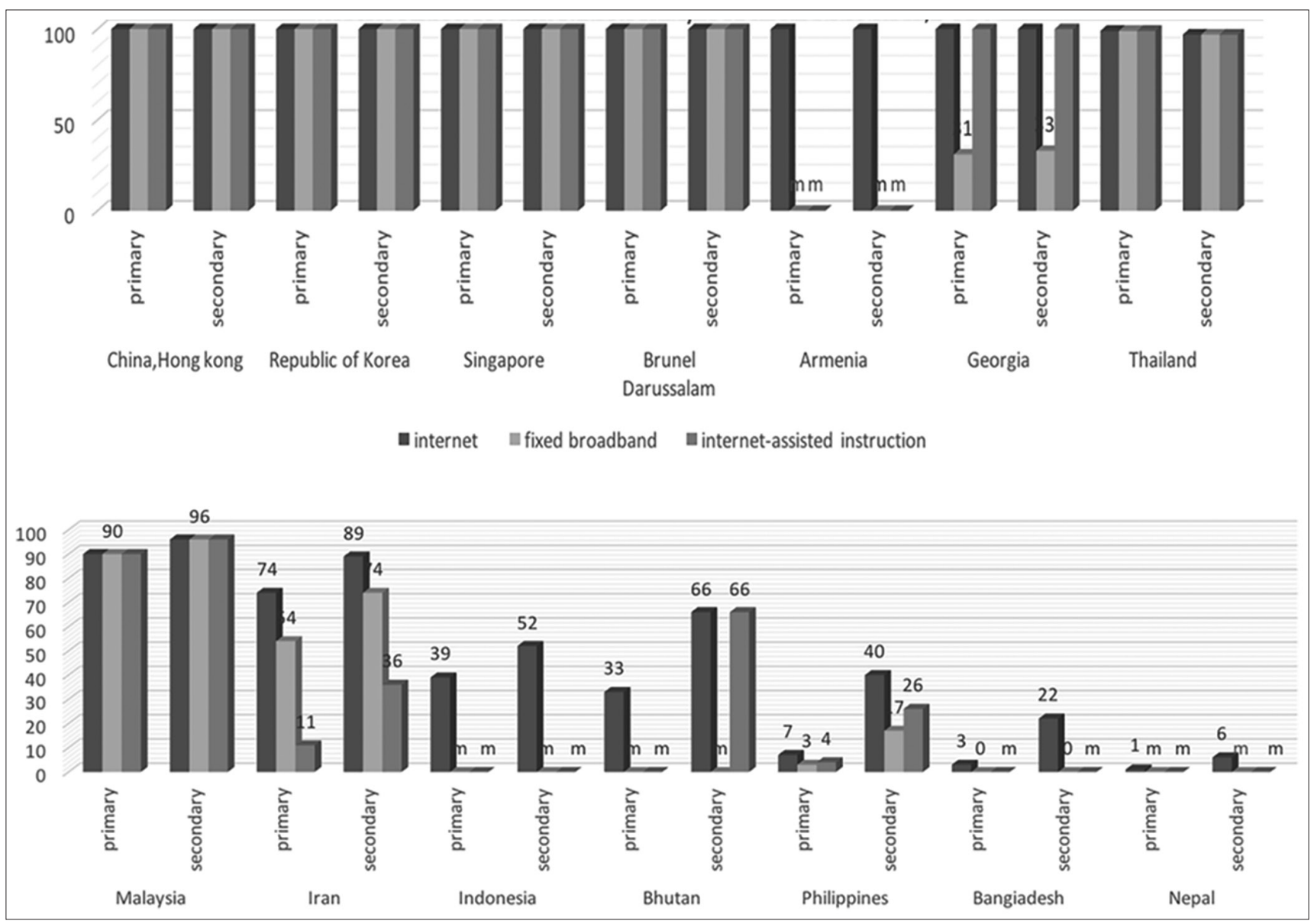

Figure 6. Proportion of educational institutions with Internet, fixed broadband and Internet-assisted instruction by level of education, 2012

UIS (2014) also reported that pupils in Iran who use school computers to supplement learning have higher average achievement scores that are $14 \%$ and $8 \%$ greater in mathematics and science, respectively, than students with no school-based computers. However, the report noted that "schools in Iran, which are well-equipped with computers and other forms of ICT, also tended to be from regions of higher socio-economic status (SES), a factor that is consistently positively related with achievement (OECD, 2010; Willms, 2006)."

We draw the following conclusions from the above reports on the present state of ICT in Iranian educational context. First, Iran is not on the list of top ten countries with the largest percentage of digital natives. Second, Iran has a smaller proportion of internet users (almost 39 million out of 80 million) with an illiteracy rate of $16 \%$ compared with $30 \%$ of the global population between the ages of 15 and 24 years who has been online for five years or more. The largest number of Digital Natives is in South Korea (99.6\%), Japan, the USA, Finland, Denmark and the Netherlands, and the lowest number are in Timor-Leste (less than 1\%), Myanmar, Sierra Leone and other African and Asian countries, "many of which are suffering from conflict and/or have very low internet availability." However, studies also show that internet use in developing countries like Iran has grown to such an extent since 2008 that the number of digital natives is set to double by 2017 . Third, despite the growing emergence of new technologies the findings suggest that students' use of computers for teaching and learning is still quite narrow. There is no evidence that 'ICTs were pervasive in students' everyday lives, nor could they be described as being entrenched in higher education courses." Third, Iran has a significantly lower level of diffusion and use of ICT than in the developed countries (Sharma, 2003). Reportedly, the main obstacles in the growth of e-learning in Iran is not the high price of computers, but rather the lack of government budgets for equipping universities, schools and public places with new computers and suitable hardware infrastructure.(Ensafi1, Zamiri and Kahani, 2007)

As a consequence, Iran has still a long way to go before she can board Prensky's Digital Native Plane. Iranian digital natives have proved to lag behind developed countries' digital natives, and they seem to disadvantage due to disconnecting themselves from traditional tools of presentation, i.e. pen, paper and chalkboard. Witnessing the students' low achievement in schools and colleges because of their preoccupations with their electronic devices, Iranian immigrants put the blame on electronic devices and prefer to resort to their traditional "broadcast" mode of teaching. On top of that, Iranian digital immigrants have not found "interactive learning" culturally appropriate since their last bitter experience of adopting communicative language teaching in their classrooms. 


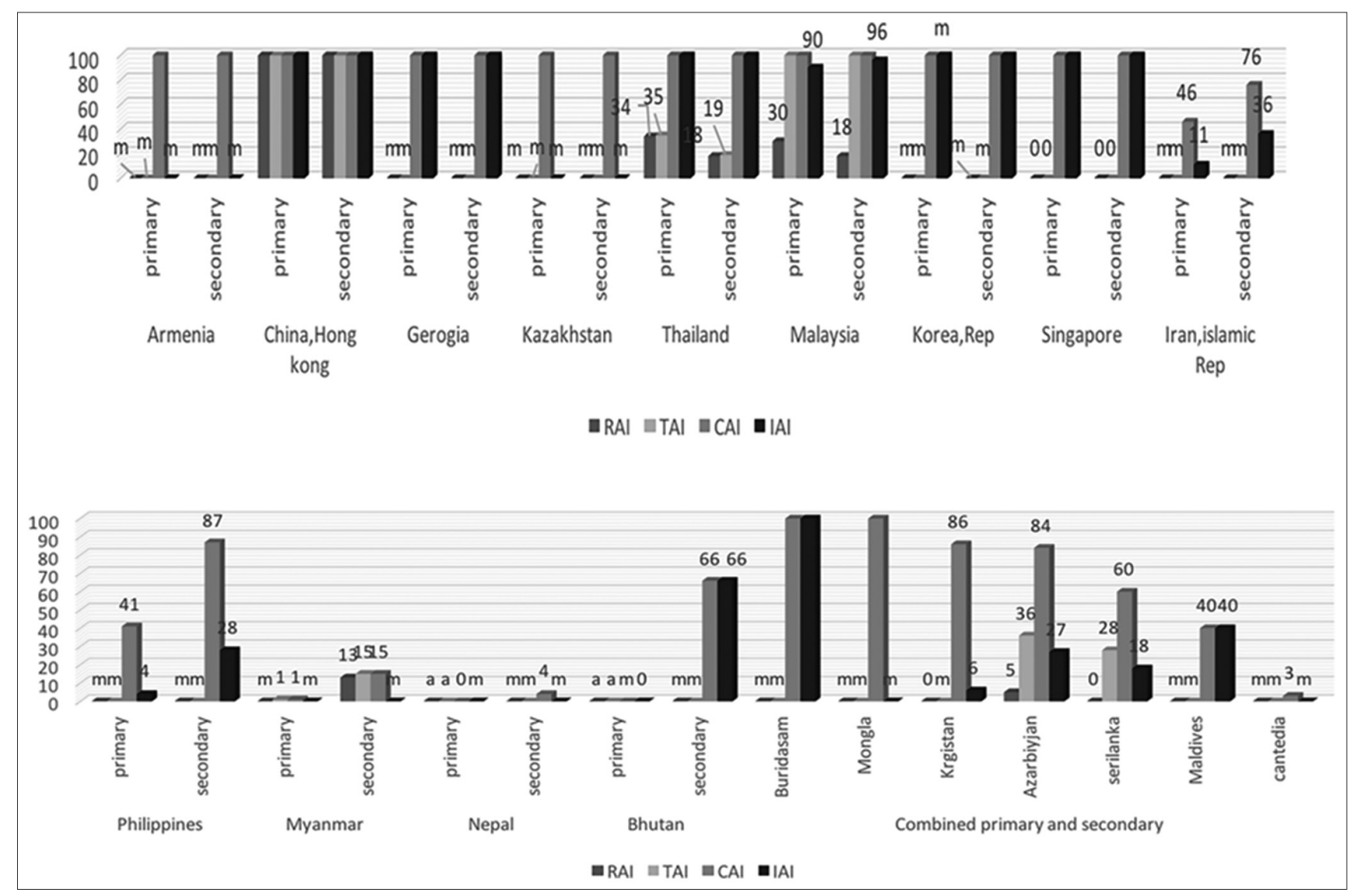

Figure 7. ICT-assisted instruction by type and level of education, 2012

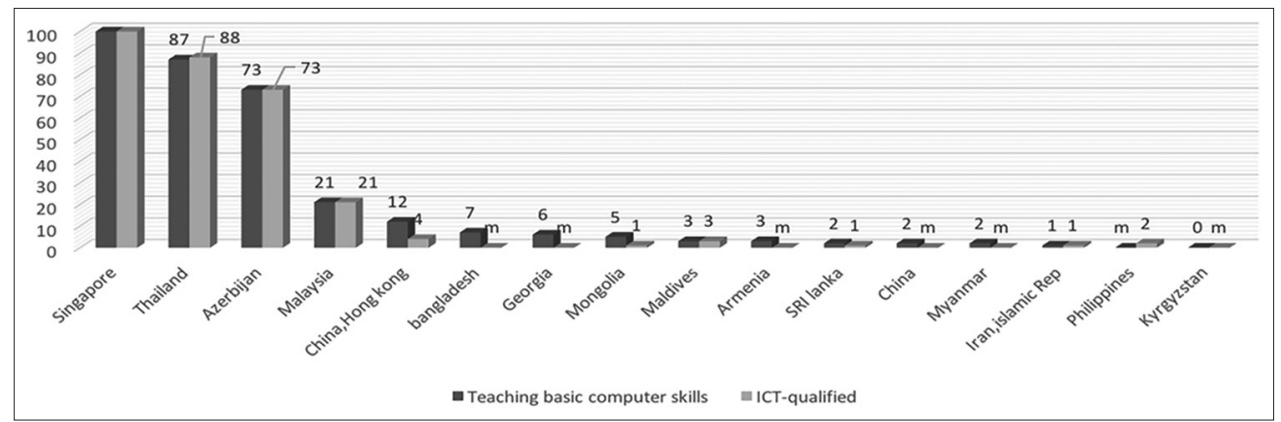

Figure 8. Proportion of combined primary- and secondary-level teachers teaching basic computer skills and subjects using ICT versus proportions trained, 2012

Adapting ICT to the context or adjust the context to ICT? Clearly the first option comes more easily to mind, perhaps because of the transitivity of the verb "contextualize" (Besse, 2011: 156). The integration of new technologies into language courses requires a more complex reality than systematic cognitive learning. It takes environmental practices, a society, institutions and history. The foregoing is a culture. We must seek a modernity that does not exclude this culture. More importantly, Iranian digital immigrants do not believe that being digitally immigrant denotes pure adherence to traditional ways of teaching but believe that digital technology is one tool among myriads of other tools which can foster learners' interaction and autonomy. As Mustafa Altun (2015) claimed, "technology does not constitute methodology, but teachers utilize technology to complement it."
Meanwhile, Wallet (2010) called to stop thinking technological contributions as simple tools in the service of pedagogy. He postulated that education can be compared to an industry and this industrial logic is only capable of transforming the teaching profession, particularly by introducing effective "programs that will free the teacher of his tedious tasks." (p.75)

\section{The Present State of ICT Integration in Education in National Research}

Besides the aforementioned reports of UNESCO Institute for Statistics (UIS, 2014) and its comparative analysis of ICT integration and e-readiness in schools across Asia, local studies as described by Iranian researchers and their institutions contribute to a sound understanding of the state of 
affairs. Because of space limitations, the examination is limited to more recent studies.

Ensafi et al. (2007) studied factors affecting the development and effectiveness of ICT in Iran's educational system, based on survey results from a group of computer engineering colleagues. Participants in the study were 22 students studying in Ferdowsi University of Mashhad, selected through a voluntary basis from a pool of students who had taken at least one web-based class at the university and were also familiar with Social Informatics, using a stratified sampling technique. The sample contained 20 to 23 years old male and female students.

The authors concluded that the development of the school curriculum and its implementation to the information age does not simply mean taking some specific actions, but referring to the change of the educational system as a whole. The authors went on to argue that such a development entails systematic change of organizations, environments, and human minds as well as physical changes toward the achievement of digital equality and all organization have to work together to make systemic change. Following ZEF Bonn (2002), they also concluded that that the key to a widespread and beneficial diffusion of ICT is to provide local content and produce local products, i.e. moving from a "network-centered phase to a content-centered one".

In addition, Ensafi et al. (2007) reported 75 percent of participants preferred the traditional modes of teaching over their new experience because as Akerlind and Trevitt (1999) argued, resistance to change is likely to be greatest when it conflicts with the students' past learning experiences, particularly when it also involves using the technology to foster a more active, self-directed style of learning. Students, adapted to teacher-dependent educational system rather than self-directed and motivated, are more comfortable with a teacher-controlled learning.

Marzaban (2011) admitted that despite advantages of using multimedia past research had found that many difficulties could preclude teachers from using ICT, such as problems in infrastructures, lack of training, book and teacher-centrism and weak technical support.

Otroshi, and Bourdet (2012), as an extension of new technologies in teaching/learning languages, wondered about the role of ICT as a key element of any current thinking related to its applicability in a particular Iranian educational culture characterized by respect for tradition. The authors examined the obstacles and the resistance that can block the practical implementation of ICT at micro and macro levels in such contexts. The authors found that a major challenge for the use of ICT at Iranian universities is the initial training of teachers. Due to lack of initial training, many teachers are afraid to integrate ICT in their teaching practice. Indeed, this is perhaps one reason that few FFL teachers possess the knowledge and skills to use technology in their teaching practice. Furthermore, the main causes of difficulties in the use of ICT for FFL were attributed to the negative attitude of teachers and their resistance to change their teaching practices. On the one hand, teachers prefer to keep a tight rein on learning, that is to say, to remain dominant due to fear of technology and its supposed powers. On the other hand, the second factor which is usually underestimated is the EFL teachers' lack of precise knowledge of the tools available. It seems that EFL teachers and professors lack sufficient knowledge and skill to use the new technologies to their advantage.

Moreover, some other constraints have been discovered, such as inadequate funding in technology, equipment and software, lack of adaptation of technology to the learning needs of teachers and students, and technical support and time. Then it seems that lack of adaptation of technology to the learning needs of teachers and students is considered one of the main factors inhibiting the use of ICT in teaching practice. This is also why the rate of use of ICT is low by teachers and students.

It is, of course, understandable that while technological applications do exist in almost all Iranian schools and colleges, teachers and students fail to use them successfully. First, there is a difference between existence and technological applications in education, particularly in the teaching of foreign languages. According to Otroshi and Bourdet (2012), the use of ICT in the teaching of French is very different from one university to another. Regarding the use of ICT in academia, the majority of university FFL professors are positive but wary of the use of ICT. However, authors reported that the major problem that limits the use of ICT in the teaching of French at universities is that there is no set policy regarding the development and support of new technologies for university professors. This is why FFL professors distrust new computer media and resort to their traditional teaching models. Ensafi, et al. (2007) observed that most teachers don't use ICT in education, though enough computer infrastructures are available for some in major universities in Iran, mostly because they are generally not aware of how ICT can be used in the learning environment. Ensafi et al. (2007) found that both students and teachers are not familiar with this new way of communication to solve their problems as more than $70 \%$ of students had preferred to ask orally rather than using e-mails to contact their teachers.

Salehi and Salehi (2012) examined the high school English teachers' perceptions of the factors discouraging teachers to use ICT in the classroom. To this end, 30 high school English teachers were selected from the five main educational districts in the city of Isfahan, Iran, to respond to a validated questionnaire. The analysis of the data revealed that insufficient technical supports at schools and little access to Internet and ICT prevented teachers to use ICT in the classroom. Moreover, shortage of class time was found to be another important discouraging factor for the teachers to integrate ICT into the curriculum.

Vajargah and Saadattlab (2014) presented the results of a feasibility assessment on implementing ICT in Tehran high schools. The results, from 362 teachers at Tehran secondary schools, identified the important areas ICT could be applied in secondary schools. The results stressed that the current conditions, equipment and resources for the application of ICT in secondary schools were not sufficient or appropriate for the successful application of ICT in secondary schools and the teachers also listed and ranked conditions, equipment and resources that they considered essential to the future of ICT in secondary schools. 
Ebrahimi (2016) examined the effect of digital reading on reading comprehension of English short prose texts of English as a Foreign Language (EFL) and English as Second Language (ESL) college students. The findings indicated that integrating digital reading program to literature programs could help students improve reading comprehension. However, the author overlooked the obstacles in implementing technology in the Iranian context.

Sullivan and Lindgren (2002, as cited in Aryadoust et al. 2016) differentiated low-source settings (developing countries) from high-source settings (developed countries) and referred to factors which prevent CALL from producing favorable results. The first group of factors is external and comprises poor or inconsistent internet connectivity, insufficient technical support, lack of required training, and limited computer accessibility. The second group of factors is internal and includes teachers' and learners' negative attitudes towards computers.

To sum up, local studies have classified the obstacles in implementing ICT in language classrooms into eight main categories to date: Lack of confidence, insufficient or lack of competence, resistance to change, lack of time, lack of effective training, insufficient or lack of technical supports, limited computer accessibility, and negative attitudes.

\section{The Present State of ICT Integration in Education in International Research}

Despite the widespread proposal that technology should play an increasingly prominent part in contemporary education to suit the needs of today's young people, there was a growing sense amongst researchers that this reform of higher education had been predicated on assumptions about the demand from students for the extensive use of new technologies in education (Jones, C. and Shao, B., 2011, p. 12). Broad et al. (2004) believed that technology integration in UK institutions had been driven by "internal political pressure" rather than empirically sound evidence (p. 137). Others have argued that the discourse that surrounds the Digital Natives debate can be compared to "an academic form of moral panic" (Bennett et al., 2008). Bennett et al. (2008) concluded that there was a need for critical enquiry and the collection of a sound body of evidence before proclaiming the need for widespread or radical change.

Reviewing the empirical studies focusing on university students' use of technologies in a range of different countries and contexts, Jones, C. and Shao, B. (2011) concluded that contemporary young students are a mixture of groups with various interests, motives, and behaviors, and that they can never be abridged into a single group or generation of students with common characteristics.

\section{RESEARCH FINDINGS AGAINST ICT INTEGRATION: ONSCREEN TEXT VERSUS WORDS ON THE PAPER:}

Since 1980s researchers have been trying to find out whether people read as attentively and comprehensively on screens as they do on paper. Answers to this riddle ultimately determine success or failure of ICT integration in schools and colleges around the world. Copious research findings suggest that paper is much superior and will never be replaced by screens.

The findings of many researchers in the field especially Sakar and Ercetin (2005), Wastlund, Reinikka, Norlander, \& Archer (2005), Uso and Ruiz (2009), Rice (1994), Kleimann (1987), and Ridder (2000) have shown no significant difference between the two modes of presentation (paper vs. computer). More importantly, Daniel Willingham (2016) disapproves of utilizing technology in education when he maintained that "the research literature consistently shows a small cost to comprehension when students read from a screen. "'(p. 12) As a result, failure of paper may be one major cause of unsuccessful implementation of ICT in many situations.

Additionally, it is unfortunate that while reading is a fundamental skill that defines the academic success or failure of students, past research has reported the supremacy of paper over screen and the failure of technology-supported reading. To date, previous studies have reported the following results:

1. Task interference between modes of presentation causes deleterious effects (Chun \& Plass' 1997).

2. Reading and working with a computer results in a higher cognitive workload and higher levels of experienced stress and tiredness compared with those reading from paper (Wastlund, Reinikka, Norlander, \& Archer, 2005).

3. The hypertextual nature of online reading develops a flexible pattern which fosters greater cognitive effort on the part of the readers since they have to construct information frameworks based on the nature of the paths chosen (Spires \& Estes, 2002).

4. Students might not be well adapted to online reading.

5. Students vary in their background knowledge, reading skills, and confidence.

6. Anecdotal evidence points to the role of spatial information in comprehension and memory. It's long been known that, when reading, spatial information seems to hitch a free ride-we can remember where something appeared in a book or even on a page, even though we did not much think about it when reading (Hasher \& Zacks, 1979). People seem to feel that reading on screen lacks that feeling of spatial localization.

7. Reading from a screen is a bit tougher, and that difficulty seems to be exacerbated as the material becomes more fact-laden (Rasmussen, 2015).

8. Students like screens for leisure reading (Foasberg, 2014) and report that they appreciate the convenience of online reading when travelling, or when they don't want others to know what they are reading (Scholastic Publishers, 2014).

9. When it comes to textbooks, students want paper (Foasberg, 2014; Mizrachi, 2015; Olsen et al, 2013; Shepperd, Grace \& Koch, 2008). In some studies, students report greater fatigue after reading electronic textbooks, so that, as much as the comprehension difference, may drive their preference (Woody, Daniel \& Baker, 2010).

10. Fewer studies have compared screen and paper when reading narratives, but existing studies echo the textbook studies-paper is better (Rasmusson, 2015; Zucker 
et al, 2009). One study reported readers are less likely to say they are "transported" to the fictional world when reading on a screen (Mangen \& Kuiken, 2014).

11. There are fewer studies of K-12 students reading academic texts, but at least two studies report the same finding: paper beats screens (Kim \& Kim, 2013; Mangen et al, 2013).

12. When experimenters limit reading time, comprehension is better with the paper version (Chen et al, 2014).

13. The comparison has most often been made in college students reading academic materials. In these studies students are asked to read a passage from an electronic textbook and then answer questions about the passage, either with or without access to the text. The consistent finding is that reading on paper is more efficient, that is, comprehension is the same, but students are able to read the paper version more quickly (Ackerman \& Lauterman, 2012; Connell et al, 2012; Daniel \& Woody, 2013).

14. Findings suggest that the skepticism towards digital reading media may reflect a general cultural attitude towards reading in this manner rather than measurable cognitive effort during reading (Kretzschmar et al. 2013)

15. Mangen et al. (2013) say that paper gives spatio-temporal markers while you read. Touching paper and turning pages aids the memory, making it easier to remember where you read something. Having to scroll on the computer screen makes remembering more difficult.

16. In their study, Ackerman and Lauterman (2012) concluded that the problem with screen reading is more psychological than technological. But the study also argues that medium preferences matter, since those who studied on their preferred medium showed both less overconfidence and got better test scores.

17. Waters, J, Roach, J, Emde, J, McEathron, S and Russell, K (2014), in a comparison of e-book and print book discovery, preferences, and usage by science and engineering faculty and graduate students at the university of Kansas, concluded that when students have to read e-books, they get used to them, discover their benefits and start to like them. Since most libraries cannot afford to purchase all books in each format some users will have to read books on a medium other than their preferred one. Then, if we manage to make them accessible to our users, perhaps there will eventually be no problem.

18. Tseng (2014) investigated the difficulties of reading text on the web for EFL learners. Tseng found that the major difficulties students experienced when reading text on the web were: they experienced eyestrain, they skipped lines, and they could not take notes or underline any words or text on computer screens.

19. Evidence from laboratory experiments, polls and consumer reports indicates that modern screens and e-readers fail to adequately recreate certain tactile experiences of reading on paper that many people miss and, more importantly, prevent people from navigating long texts in an intuitive and satisfying way. In turn, such navigational difficulties may subtly inhibit reading comprehension.(Jabr, 2013, p.2)
20. Many people approach computers and tablets with a state of mind less conducive to learning than the one they bring to paper. (Jabr, 2013)

21. Compared with paper, screens may also drain more of our mental resources while we are reading and make it a little harder to remember what we read when we are done. (Wstlund, 2005, cited in Jabr, p.2)

22. "There is physicality in reading.....maybe even more than we want to think about as we lurch into digital reading-as we move forward perhaps with too little reflection. I would like to preserve the absolute best of older forms, but know when to use the new." (Wolf M., 2014, cited in Jabr. 2013, p.2)

23. "In most cases, paper books have more obvious topography than onscreen text. An open paperback presents a reader with two clearly defined domains-the left and right pages-and a total of eight corners with which to orient oneself. A reader can focus on a single page of a paper book without losing sight of the whole text: one can see where the book begins and ends and where one page is in relation to those borders." (Jabr, 2013, p.4)

24. Screens and e-readers interfere with two other important aspects of navigating texts: "serendipity and a sense of control" (Olsen, 1994, cited in Jabr, 2013, p.5). People report that they enjoy flipping to a previous section of a paper book when a sentence surfaces a memory of something they read earlier, for example, or quickly scanning ahead on a whim. People also like to have as much control over a text as possible-to highlight with chemical ink, easily write notes to themselves in the margins as well as deform the paper however they choose. Because of these preferences-and because getting away from multipurpose screens improves concentration-people consistently say that when they really want to dive into a text, they read it on paper." (Gerlach and Buxmann, 2011, cited in Jabr, 2013, p.5)

25. Digital texts do not have not satisfyingly replicated the tactility of paper-based texts. Onscreen text is far more intangible than text on paper. Whereas a paper book is made from pages of printed letters fixed in a particular arrangement, the text that appears on a screen is not part of the device's hardware-it is an "ephemeral image."(Jabr, 2013)

26. Paper books have a discernible size, shape and weight, whereas electronic books lack obvious shape or thickness. Such discrepancies create enough "haptic dissonance" to dissuade some people from using e-readers. People expect books to look, feel and even smell a certain way; when they do not, reading sometimes becomes less enjoyable or even unpleasant.(Gerlach and Buxmann, 2011, cited in Jabr, 2013)

27. Since reading on screen "is more physically and mentally taxing" than reading on paper, people comprehend less when they read on a screen. E-ink is easy on the eyes because it reflects ambient light just like a paper book, but computer screens, smartphones and tablets like the iPad shine light directly into people's faces due to their glare, pixilation and flickers." (Wstlund, 2005, cited in Jabr, 2013) 
28. "Prolonged reading on glossy self-illuminated screens can cause eyestrain, headaches and blurred vision." (Jabr, 2013)

29. "E-readers and tablets are becoming more popular as such technologies improve, but research suggests that reading on paper still boasts unique advantages." (Jabr, 2013)

30. "An eternal fear: the fear that a new technological achievement could abolish or destroy something that we consider precious, fruitful, something that represents for us a value in itself, and a deeply spiritual one." (Eco, 1996, p.4)

31. "Books will remain indispensable not only for literature, but for any circumstance in which one needs to read carefully, not only to receive information but also to speculate and to reflect about it. To read a computer screen is not the same as to read a book." (Eco, 1996, p.12)

32. "Up to now, books still represent the more economical, flexible, wash-and-wear way to transport information at a very low cost." (Eco, 1996, p.13)

33. "Technology at best only amplifies the pedagogical capacity of educational systems; it can make good schools better, but it makes bad schools worse." (Toyama, 2011, "There Are No Technology Shortcuts," para.4)

34. "Many good school systems excel without much technology." (Toyama, 2011, "There Are No Technology Shortcuts," para.4)

Additionally, opponents of using computers in teaching languages present different reasons for their stand. Some of them are:

- no "free expression": Due to the present limitations of hardware and software computers can handle a word, a phrase and a sentence, but they cannot judge very long and very complex sentences. (Lucchi, 2011)

- High implementation costs

- Trivial material implying trivial question and answer drills

- Reluctance, technophobia, and on the part of teachers a fear of losing face by having less technological expertise than students (Chambers \& Bax, 2006).

All of the evidence stands on its own, but after tying them together the following general conclusions can be drawn from their analysis: there can be a negative side resulting from inappropriate or underuse of technology and that negative side can have serious and long-term consequences. Besides, using technology is a cultural act and there are countries in which schools and colleges perform exceptionally well without much technology.

\section{DISCUSSION}

Iranian EFL teachers are advised to consider what computer industry offers for their classrooms, and should consequently motivate their students to use them efficiently and wisely after necessary training. Using technology does not necessarily mean EFL teachers should prohibit traditional printbased reading, but instead, they should seek their students learning preferences and needs and take subsequent mea- sures accordingly. As it was mentioned before, EFL teachers are recommended to take into account all factors including environmental factors, cultural factors, socioeconomic factors, age, gender, linguistic background, accessibility, acceptability, and learning preferences and styles before incorporating computer technology. Otherwise, blindfold consent to use technology in any EFL context without considering the above-mentioned factors would lead to fallacies.

Moreover, technology tools, like methods, should not be used mechanically but should be context specific. It would be a mistake to believe that some developing countries like Iran can mirror English-dominant as well as technology-dominant contexts such as the US, Japan, Chile and Singapore. Developing countries need to develop more technological capability and greater flexibility to facilitate the first use of new technology in the local context. As Selwyn (2013).stated, "digital technologies are shaped by the social contexts in which they are implemented" (p.21) and by this, he suggests that we need to consider the influence of issues such as language and religion. Selwyn (2013).also argues that educational technology needs to be viewed in the broader political, economic, social, cultural and historical contexts of the countries in which it is being implemented. Furthermore, Osin (1998) took context into account when he stated that "he tried to avoid the usual pitfall of many transfer-of-technology projects, which is to "copy" in a developing country a project that was successful in a developed country." Osin also asserts:

"In developing countries, with large segments of the population living at extreme levels of poverty, the first question that must be asked is whether it is reasonable to invest money in technology for the educational system, instead of using the same money to improve the living conditions of those in dire need. I believe that these interests are not contradictory and that the only way to reach a long-term solution for the economic problems of the population is to raise the educational level, particularly for the low socio-economic groups.” (p.2)

Further, Osin observes that competitiveness in international markets relies more on the educational level of human resources than on raw materials, and automation of industrial and commercial processes has made personnel migrate towards more intellectually challenging tasks. Therefore, the present educational system has the responsibility to provide the graduates at the levels needed for such tasks.

Nevertheless, developing countries are more likely to derive greater benefit from computer technology in education if the so-called "digital natives" of these countries were trained to use their digital literacy for the benefit of their education rather than for fun and communication. Prensky(2001) contends that our students are all native speakers of the digital language of computers, video games and the Internet and his argument is based on the assumption that the "thinking patterns" of these speakers have changed. However, Prensky is talking about the US and similar developed countries, and he does not generalize about all countries in the world. Following such trends of thoughts 
which is context-specific by no means guarantees the desired outcome in a developing country like Iran. Technology alone cannot improve the delivery of knowledge; a new computer cannot make a teacher better. Nor can it provide a magic formula to improve learning; a new pencil does not make a child better at writing essays (Cuban, 1986, 2001). Technology itself "does not bring about reform, but instead tends to amplify extant beliefs and practices" (Warschaucer, 2011, p. 115). Once education is improved, we can expect technology to accelerate the process. Jobs (as cited in Wolf, 1996) once said in an interview that "what's wrong with education cannot be fixed with technology." Throwing technology at the problem of education today based on the highly emotive and often ambiguous terms such as "digital education revolution" and "digital natives" does little to address the underlying social, economic pedagogical challenges that instead deserve the full attention of education reformers (Gee, 2003, 2004; Gee and Hayes, 2011; Selwyn, 2011a, 2011b). The slow pace of technological revolution and breakthroughs in some developing countries makes the slow pace of EFL learners' thinking pattern. Educational systems are resistant to change, and a transformation that purports to accelerate the solution of the problems requires the support of educational technology (Osin, 1998). However, this technology should supplement not supplant teachers (Balajthy, 1996b) or more traditional forms of reading instruction (D'Silva, 2006, p.15).

Technology has been reported to have slowed down the progress of students in schools and colleges. Besides, a significant body of research has also made clear that most EFL teachers have been slow to transform the ways they teach, despite the influx of new technology into their context. Computers can be an expensive waste of time unless teachers integrate them appropriately to meet students' needs. Informed, flexible, dedicated teachers remain the key to effective instruction (Balajthy, 1999). In addition, there remains limited evidence to show that technology and online learning are improving learning outcomes for most EFL students. Many people argue the computer does all the work for the students, not allowing them the opportunity to digest what they have learned. Boyle (1998) argues that information technology "may actually be making us stupid." (p. 618). He argues that the computer takes more of the thinking process out of students. Furthermore, teachers and parents alike have expressed concerns about digital distractions, "ways in which unequal access to and use of technology might widen achievement gaps." Meanwhile, with each advantage comes a potential cost. When we understand those costs and can minimize them, we can keep the use of technology positive.

Eventually, Beniger (1989) and Postman (1995) warn against the overuse or misuse of technology:

"We proceed under the assumption that information is our friend, believing that cultures may suffer grievously from a lack of information, which, of course, they do. It is only now beginning to be understood that cultures may also suffer grievously from information glut, information without meaning, information without control mechanisms." (Beniger, 1989, p. 70)

\section{CONCLUSION}

On the basis of the evidence to the contrary, it could be argued that there are ostensibly lots of computer infrastructure and millions of so-called digital natives out there in Iran. However, delving more deeply into diverse reports not only uncovers the true proportion of Iranian digital natives but also indicates how misapplication or underutilization of computer technology can lead to a pretense of novelty and academic literacy. By implication, "Digital Natives" claim made by Prensky (2001) looks more like a myth than a theory in Iran and the notion cannot be generalized about this country. It would hardly be safe to generalize upon data from high-source settings. Such overgeneralizations can in fact be counterproductive as their psychological overload might result in imposition of technology in low-source settings which in turn leads to technophilia at the expense of human interaction, bibliophobia, Papyrophobia, pedagophobia, and eventually tech-rejection. Doubtlessly, even If technology does not cut Iranian students off from the rest of the world, misapplication of technology does.

\section{REFERENCES}

Akerlind, Gerlese S., and A. Chris Trevitt. 1999. "Enhancing self-directed learning through educational technology: When students resist the change." Innovations in Education and Training International 36: 96-105.

Ackerman, Rakefet, and Tirza Lauterman. 2012.’Taking reading comprehension exams on screen or on paper? A metacognitive analysis of learning texts under time pressure." Computers in human behavior 28: 1816-1828.

Altun, Mustafa. 2015."The integration of technology into foreign language teaching." International Journal on New Trends in Education and Their Implications 6: 22-27.

Aryadoust, V., Mehran, P., \& Alizadeh, M. 2016. "Validating a computer-assisted language learning attitude instrument used in Iranian EFL context: an evidence-based approach." Computer Assisted Language Learning 29: 561-595.

Balajthy, Ernest. 1996."Software Classifications: Trends in Literacy Software Publication and Marketing."

Bennett, Sue, Karl Maton, and Lisa Kervin. 2008."The 'digital natives' debate: A critical review of the evidence." British journal of educational technology 39: 775-786.

Berry, Bruce D. 2001.”Digital Natives, Digital Immigrants, Part II: Do They Really Think Differently? By Marc Prensky From On the Horizon (NCB University Press, Vol. 6, December 2001) 1. 9 No."

BESSE, Henri. 2011."Six remarques autour et au-delà de la contextualisation du CECR." Le Français dans le Monde, Recherches et applications 50:150-162.

Broad, Martin, Martin Matthews, and Andrew McDonald. 2004."Accounting education through an online-supported virtual learning environment." Active Learning in Higher Education 5: 135-151.

Carstens, Adam, and John Beck. 2005."Get ready for the gamer generation." TechTrends 49: 22-25. 
Chambers, Andrea, and Stephen Bax. 2006. "Making CALL work: Towards normalisation.” System 34: 465-479.

Chen, Guang, Wei Cheng, Ting-Wen Chang, Xiaoxia Zheng, and Ronghuai Huang. 2014."A comparison of reading comprehension across paper, computer screens, and tablets: Does tablet familiarity matter?" Journal of Computers in Education 1: 213-225.

Chun, Dorothy M., and Jan L. Plass. 1997.'Research on text comprehension in multimedia environments." Language learning \& technology 1: 60-81.

Connell, Louise, and Dermot Lynott. 2012.'When does perception facilitate or interfere with conceptual processing? The effect of attentional modulation." Frontiers in Psychology 3.474.

Cuban, Larry. 1986. Teachers and machines: The classroom use of technology since 1920. Teachers College Press.

Cuban, Larry. 2001. How can I fix it? Finding solutions and managing dilemmas: An educator's road map. Teachers College Press.

Dada, Danish. 2006. "E-readiness for developing countries: Moving the focus from the environment to the users." The Electronic Journal of Information Systems in Developing Countries 27.

Daniel, David B., and William Douglas Woody. 2013. "E-textbooks at what cost? Performance and use of electronic v. print texts." Computers \& Education 62: 18-23.

Dede, C. 2005a. "The need for new strategies of education reform." Harvard ED Magazine 48: 28-29.

Dede, Chris. 2005. "Planning for neomillennial learning styles: Implications for investments in technology and faculty." Educating the net generation 5.

De Ridder, Isabelle. 2000. "Are we conditioned to follow links? Highlights in CALL materials and their impact on the reading process." Computer Assisted Language Learning 13: 183-195.

D'Silva, Reginald. 2006. "Reading by bits and bytes: the use of computer reading software in classrooms." English Quarterly Canada 38.15.

Ebrahimi, Shirin Shafiei. 2016. "Effect of Digital Reading on Comprehension of English Prose Texts in EFL/ESL Contexts." International Journal of English Language and Literature Studies 5: 111-117.

Eco, Umberto. 1996. "From internet to Gutenberg." In Conferência proferida em 12.

Ensafi, Roya, Amin Zamiri, and Mohsen Kahani. 2007. "ICT challenges in education. Reflections from a developing country: Iran, with reference to the statistics from computer science students." In The $2^{\text {nd }}$ International Conference on Virtual Learning, Ferdowsi University, Mashhad, Iran.

Foasberg, Nancy M. 2014. "Student reading practices in print and electronic media." College \& Research Libraries 75: 705-723.

Gee, James Paul. 2003. "What video games have to teach us about learning and literacy." Computers in Entertainment (CIE) 1: 20-20.

Gee, James Paul. 2004. Situated language and learning: A critique of traditional schooling. Psychology Press.

Gee, J. P., \& Hayes, E. R. Language and learning in the digital age. Routledge, 2011.
Hasher, Lynn, and Rose T. Zacks. 1979. "Automatic and effortful processes in memory." Journal of experimental psychology: General 108.356.

Howe, Neil, and William Strauss. 2009. Millennials rising: The next great generation. Vintage.

Islamic Republic of Iran. 2012. "Country report on ICT in education." Tehran: Ministry of Education.

Jabr, Ferris. 2013. "The reading brain in the digital age: The science of paper versus screens." Scientific American 11.

Jones, Christopher. 2011. "Students, the net generation, and digital natives." Deconstructing digital natives: Young people, technology, and the new literacies: 30-45.

Jones, Christopher, and Binhui Shao. 2011."The net generation and digital natives: Implications for higher education. York: Higher Education Academy."

Jorgensen, Bradley. 2003. "Baby Boomers, Generation X and Generation Y? Policy implications for defence forces in the modern era." foresight 5: 41-49.

Kleinmann, Howard H. 1987. "The Effect of Computer-Assisted Instruction on ESL Reading Achievement." The Modern Language Journal 71: 267-276.

Kretzschmar, Franziska, Dominique Pleimling, Jana Hosemann, Stephan Füssel, Ina Bornkessel-Schlesewsky, and Matthias Schlesewsky. 2013. "Subjective impressions do not mirror online reading effort: Concurrent EEG-eyetracking evidence from the reading of books and digital media." PloS one 8: e56178.

Lenhart, Amanda, Lee Rainie, and Oliver Lewis. 2001. "Teenage Life Online: The Rise of the Instant-Message Generation and the Internet's Impact on Friendships and Family Relationships. Retrieved August 24, 2008."

Lucchi, Nicola. 2011. "Access to Network Services and Protection of Constitutional Rights: Recognizing the Essential Role of Internet Access for the Freedom of Expression."

Mangen, Anne, and Don Kuiken. 2014. "Lost in an iPad: Narrative engagement on paper and tablet." Scientific Study of Literature 4: 150-177.

Margaryan, Anoush, Allison Littlejohn, and Gabrielle Vojt. 2011. "Are digital natives a myth or reality? University students' use of digital technologies." Computers \& Education 56: 429-440.

Marzban, Amir. 2011. "Investigating the role of multimedia annotations in EFL reading comprehension." Procedia-Social and Behavioral Sciences 28: 72-77.

McCrindle, Mark. 2006.New generations at work: Attracting, recruiting, retaining and training generation $Y$. The $\mathrm{ABC}$ of XYZ.

Mizrachi, Diane, and Marcia J. Bates. 2013. "Undergraduates' personal academic information management and the consideration of time and task-urgency." Journal of the American Society for Information Science and Technology 64: 1590-1607.

Oblinger, Diana. 2003. "Boomers gen-xers millennials." EDUCAUSE review 500: 37-47.

Oblinger, Diana, James L. Oblinger, and Joan K. Lippincott. 2005. Educating the net generation. Boulder, Colo.: EDUCAUSE, c2005. 1 v.(various pagings): illustrations. 
Osín, Luis. 1998. Computers in education in developing countries: Why and how? Education and Technology Team, Human Development Network, World Bank.

Otroshi, Mohamad-Hossein, and Jean-François Bourdet. 2012. "ICT and the Problem of Integration in the Teaching/Learning of French as a Foreign Language in Iran." In International Conference: ICT for Language Learning.

Palfrey, John Gorham, and Urs Gasser. 2013. Born digital: Understanding the first generation of digital natives. Basic Books.

Postman, Neil. 1995. "Making a Living, Making a Life: Technology Reconsidered." College Board Review 176: 8-13.

Prensky, Marc. 2001. "Digital natives, digital immigrants part 1." On the horizon 9: 1-6.

Rice, Gary E. 1994. "Examining constructs in reading comprehension using two presentation modes: Paper vs. computer." Journal of Educational Computing Research 11: $153-178$.

Sakar, Asim, and Gulcan Ercetin. 2005. "Effectiveness of hypermedia annotations for foreign language reading." Journal of Computer Assisted Learning 21: 28-38.

Salehi, Hadi, and Zeinab Salehi. 2012."Integration of ICT in language teaching: Challenges and barriers." In Proceedings of the $3^{\text {rd }}$ International Conference on e-Education, e-Business, e-Management and e-Learning (IC4E, 2012), IPEDR 27: 215-219.

Selwyn, Neil. 2011.'It's all about standardisation'-Exploring the digital (re) configuration of school management and administration." Cambridge Journal of Education 41: 473-488.

Selwyn, Neil. 2010. Schools and schooling in the digital age: A critical analysis. Routledge.

Selwyn, Neil. 2012. Education in a digital world: Global perspectives on technology and education. Routledge.

Shepperd, James A., Jodi L. Grace, and Erika J. Koch. 2008. "Evaluating the electronic textbook: Is it time to dispense with the paper text?." Teaching of Psychology 35: 2-5.

Spires, HILLER A., and THOMAS H. Estes. 2002. "Reading in web-based learning environments." Comprehension instruction: Research-based best practices: 115-125.

Stoerger, Sharon. 2009. "The digital melting pot: Bridging the digital native-immigrant divide." First Monday 14.7.

Strauss, William, and Neil Howe. 2000. "Millennials rising: The next great generation." New York: Vintage.

White, D. 2008. "Not «Natives» \& «Immigrants» but «Visitors» \& «Residents». TALL blog Online education with the University of Oxford (Entrada de blog)."

Tapscott, Don. 1999. "Educating the net generation." Educational leadership 56: 6-11.

Tapscott, Don. 2008. Grown up digital: How the net generation is changing your world HC. McGraw-Hill.

Tapscott, Don, and Anthony D. Williams. 2010. "Innovating the $21^{\text {st }}$-century university: It's time!." Educause review 45: 16-29.
Toyama, Kentaro. 2011. "There are no technology shortcuts to good education." Educational Technology Debate 8.

Tseng. 2008. "Difficulties of Reading Text on the Web." The Internet TESL Journal 14.2.

UNESCO Institute for Statistics. 2014. Information and communication technology (ICT) in Asia: A comparative analysis of ICT integration and e-readiness in schools in Asia. Montreal: UIS.

Usó, Esther, and M $\mathrm{M}^{\mathrm{a}}$ Noelia Ruiz-Madrid. 2009. "Reading printed versus online texts. A study of EFL learners strategic reading behavior." International Journal of English Studies 9.2.

VAJARGAH, Kourosh FATHI, and Ayat Saadattlab. 2014. "A feasibility study of using ict in Iranian secondary schools: The case of Tehran province." TOJET: The Turkish Online Journal of Educational Technology 13.3. Veen, Wim. 2003. "A new force for change: Homo Zappiens."

Warschauer, Mark. 2011. Learning in the Cloud. Teachers College Press.

Wästlund, Erik, Henrik Reinikka, Torsten Norlander, and Trevor Archer. 2005. "Effects of VDT and paper presentation on consumption and production of information: Psychological and physiological factors." Computers in Human Behavior 21:377-394.

Waters, Julie, Jennifer Roach, Judith Emde, Scott R. McEathron, and Keith Russell. 2014. "A Comparison of E-book and Print Book Discovery, Preferences and Usage by Science and Engineering Faculty and Graduate Students at the University of Kansas."

Weiler, Angela. 2005. "Information-seeking behavior in generation Y students: Motivation, critical thinking, and learning theory." The Journal of Academic Librarianship 31: 46-53.

Weller, Jacques. 2010. "Technologie et gouvernance des systèmes éducatifs dans Apprendre avec les Technologies."

Willingham, Daniel. 2016. "Response: Reading Digitally vs. Reading Paper." Posted by Larry Ferlazzo on May 28, 2016 10:50 AM. Retrieved from: http://blogs.edweek.org/teachers/classroom_qa_with_larry_ferlazzo/2016/05/response_reading_digitally_vs_reading_paper.html? intc $=$ main- $\bar{m}$ psmvs.

Wolf, Gary. 1996. "Steve Jobs: The next insanely great thing." Wired Magazine, 50-55.

Woody, William Douglas, David B. Daniel, and Crystal A. Baker. 2010. "E-books or textbooks: Students prefer textbooks." Computers \& Education 55: 945-948.

ZEF Bonn. 2002. "Information and Communication Technologies for Development." The Center for Development Research, University of Bonn.

Zucker, Tricia A., Amelia K. Moody, and Michael C. McKenna. 2009. "The effects of electronic books on pre-kindergarten-to-grade 5 students' literacy and language outcomes: A research synthesis." Journal of Educational Computing Research 40: 47-87. 